\title{
The influence of lithium carbonate on the heat release during the hydration of Portland cement at the temperature $40^{\circ} \mathrm{C}$
}

\author{
Anisa Kuzina ${ }^{1}$, Ekaterina Shokodko ${ }^{1}$, Andrey Pustovgar ${ }^{1}$, and Aleksey Adamtsevich ${ }^{1, *}$ \\ ${ }^{1}$ Moscow State University of Civil Engineering, 26 Yaroslavskoye Sh., Moscow, 129337, Russia
}

\begin{abstract}
This work represents the stage of the author's research aimed at identifying the solutions for increasing the energy efficiency of the production of precast concrete and reinforced concrete products and structures in plant conditions due to reducing the temperature of heat treatment, or due to the reduction of duration of this technological process. The work provides results of the research of the influence of the admixture of lithium carbonate $\left(\mathrm{Li}_{2} \mathrm{CO}_{3}\right)$ on the dynamics of hydration process of the binding systems on a cement basis in the conditions of the increased temperature $\left(40^{\circ} \mathrm{C}\right)$. The research was performed using the method of isothermal calorimetry on the two various samples of the cement binder, conducted in various countries. The $\mathrm{Li}_{2} \mathrm{CO}_{3}$ admixture is accepted in dosages from $0.5 \%$ to $2.5 \%$. The graphical dependence of the heat flow of the exothermic reaction of hydration on the used lithium carbonate dosage in the first days of curing of the samples is established and presented.
\end{abstract}

\section{Introduction}

The accelerated pace of development of the industry of the construction materials necessitates the need of the optimization of the production processes, the improvement of the recipes and the search for new approaches to the solution of the practical tasks. The issue of decreasing the energy costs at the plants of the concrete-panel construction is becoming more and more relevant. The optimal selection of the concrete mix and the introduction of the modifying admixtures providing the products' strength development at early stages and the increased thermal emission allow to provide the energy saving at the stage of the hygrothermal processing of products, while maintaining the previous level of the mould reusability $[1,4]$.

For a long time in the construction industry the admixtures regulating the setting rate and hardening of the cement systems have been the most widespread, and among them there are: the sodium chloride, the soda ash, the sodium thiosulphate, etc. However, since the chlorine ions can cause the corrosion of reinforcing steel, the chlorine-containing accelerating agents of hardening practically have practically ceased to apply in the industrial production of the concrete products.

At the same time, the sodium salts cause the efflorescence on the surface of the concrete products $[3,7,11]$, negatively impacting the trade dress of the manufactured products. In this

* Corresponding author: AdamtsevichAO@mgsu.ru 
regard, today the increasing relevance is acquired by the search of the effective accelerators which, on the one hand, have the high accelerating effect even at low dosages, and on the other hand, do not contain chlorine and do not negatively impact on the appearance of the manufactured concrete and reinforced concrete products and constructions.

One of the admixtures having the potential of broader application at the plants of the reinforced concrete goods production is the lithium carbonate $\left(\mathrm{Li}_{2} \mathrm{CO}_{3}\right)$ [13].

This is due to the fact that firstly, this admixture meets the requirements listed above, and secondly, the recent researches [8] have shown that when it is used in combination with cements of domestic production, it is possible to observe the improvement of the efficiency of the admixture's effect with rising temperature regime of the storage of samples, which is capable to provide the additional synergetic effect of the introduction of the considered accelerator in the conditions of the hydrothermal processing applied by manufacture of the reinforced concrete products in plant conditions.

For the determination of the effective dosages of the admixture having the noticeable impact on kinetics of hydration of the cement binder, in the present work a series of the pilot studies aimed at identification of the dependence between the mineralogical, granulometric and phase composition of cement and also the admixture dosage has been carried out.

\section{Materials and methods}

The assessment of efficiency of the admixtures influencing the kinetics of hardening of the concrete can be executed using the various ways: the determination of the reacted phases by the XRF method [6], the determination of the chemical shrinkage [5], the determination of the amount of non-evaporable water content [4] and others.

Now rather exact determination of impact of the various modifiers on kinetics of the course of process of hydration of the cement binder can be executed by using the method of an isothermal calorimetry which is based on the measurement and the analysis of the amount of heat from the hydration of the cement phases $[5,9,10,12]$.

Thus, the determination of efficiency of the use of the admixture of lithium carbonate $\left(\mathrm{Li}_{2} \mathrm{CO}_{3}\right)$ as the accelerator of hardening of the cement binder with the application of the isothermal calorimetry method represents the research objective. For the performance of research the cements of Russian manufacture (Cement 1: PTs 500 D0) and of the European manufacture (Cement 2: class 52.5, normal hardening) have been used. Experience shows that these cements have the essential differences in their granulometric composition (table 1) and also the small differences in the mineralogical and phase compositions (table 2-3).

The determination of the granulometric composition of the samples was carried out by the method of laser diffraction using the microanalyzer of the sizes of particles "Analysette $22 "$.

The determination of the chemical and phase composition was carried out by using the X-ray fluorescence spectrometer ARLOptim'X.

Table 1. The granulometric composition of the studied samples.

\begin{tabular}{|c|c|c|c|}
\hline $\begin{array}{c}\text { Sample } \\
\text { designation }\end{array}$ & $\begin{array}{c}\text { Maximum particle size } \\
(\mathrm{d} 98), \mu \mathrm{m}\end{array}$ & $\begin{array}{c}\text { Average particle size } \\
(\mathrm{d} 50), \mu \mathrm{m}\end{array}$ & $\begin{array}{c}\text { Particle content less } \\
\text { than } 2 \mu \mathrm{m}, \%\end{array}$ \\
\hline Cement 1 & 51.617 & 16.048 & 8.55 \\
\hline Cement 2 & 42.823 & 10.762 & 11.34 \\
\hline
\end{tabular}


Table 2. Chemical and mineralogical composition of the Cement 1.

\begin{tabular}{|c|c|c|c|}
\hline \multicolumn{2}{|c|}{ Chemical composition } & \multicolumn{2}{c|}{ Mineralogical composition } \\
\hline Oxide & Content, $\%$ & Phase & Content, $\%$ \\
\hline $\mathrm{CaO}$ & 59.24 & $\mathrm{C}_{3} \mathrm{~S}$ & 64.0 \\
\hline $\mathrm{SiO}_{2}$ & 21.52 & $\beta-\mathrm{C}_{2} \mathrm{~S}$ & 13.4 \\
\hline $\mathrm{Al}_{2} \mathrm{O}_{3}$ & 5.36 & $\mathrm{C}_{3} \mathrm{~A}$ & 4.2 \\
\hline $\mathrm{MgO}$ & 3.63 & $\mathrm{C}_{4} \mathrm{AF}$ & 10.8 \\
\hline $\mathrm{SO}_{3}$ & 3.62 & $\begin{array}{c}\text { Calcium sulfate } \\
\text { hemihydrate }\end{array}$ & 2.7 \\
\hline $\mathrm{Fe}_{2} \mathrm{O}_{3}$ & 2.56 & Anhydrite & 3.7 \\
\hline $\mathrm{K}_{2} \mathrm{O}$ & 0.621 & $\mathrm{MgO}$ & \\
\hline $\mathrm{TiO}_{2}$ & 0.184 & & \\
\hline $\mathrm{Na}_{2} \mathrm{O}$ & 0.113 & & \\
\hline Other oxides & less than 0.3 & & \\
\hline $\mathrm{LOI}^{*}$ & 2.84 & & \\
\hline
\end{tabular}

Table 3. Chemical-mineralogical composition of the Cement 2.

\begin{tabular}{|c|c|c|c|}
\hline \multicolumn{2}{|c|}{ Chemical composition } & \multicolumn{2}{c|}{ Mineralogical composition } \\
\hline Oxide & Content, $\%$ & Phase & Content, $\%$ \\
\hline $\mathrm{CaO}$ & 59.47 & $\mathrm{C}_{3} \mathrm{~S}$ & 65.4 \\
\hline $\mathrm{SiO}_{2}$ & 21.10 & $\beta-\mathrm{C}_{2} \mathrm{~S}$ & 13.5 \\
\hline $\mathrm{Al}_{2} \mathrm{O}_{3}$ & 5.72 & $\mathrm{C}_{3} \mathrm{~A}$ & 4.3 \\
\hline $\mathrm{SO}_{3}$ & 4.05 & $\mathrm{C}_{4} \mathrm{AF}$ & 9.8 \\
\hline $\mathrm{Fe}_{2} \mathrm{O}_{3}$ & 2.43 & $\begin{array}{c}\text { Calcium sulfate } \\
\text { hemihydrate }\end{array}$ & 2.0 \\
\hline $\mathrm{MgO}_{2}$ & 1.54 & Anhydrite & 3.3 \\
\hline $\mathrm{K}_{2} \mathrm{O}$ & 1.24 & Calcite & \\
\hline $\mathrm{Na}_{2} \mathrm{O}$ & 0.264 & & \\
\hline Other oxides & less than 0.5 & & \\
\hline $\mathrm{LOI}^{*}$ & 3.45 & & \\
\hline
\end{tabular}

* Loss on ignition 
As the control sample the mixture of cement and the distilled water with the water cement relation of 0.5 mixed to a condition of the homogeneous cement paste was used.

As the test samples the cement paste with the same water-cement ratio was used, with the addition of the admixture $\mathrm{Li}_{2} \mathrm{CO}_{3}$ in the following dosages according to the cement mass: $0.5 \%, 1.0 \%, 2.5 \%$. In total, 8 samples (Table 4 ) were tested within the work.

Table 4. The tested samples.

\begin{tabular}{|c|c|c|c|c|}
\hline No. & The name of the sample & $\begin{array}{c}\text { Cement, } \% \\
\text { mass }\end{array}$ & $\begin{array}{c}\mathrm{Li}_{2} \mathrm{CO}_{3}, \\
\% \text { mass }\end{array}$ & $\begin{array}{c}\text { Water, } \\
\% \text { mass }\end{array}$ \\
\hline \multicolumn{5}{|c|}{ Cement 1} \\
\hline 1 & Cement 1 & 100 & 0.0 & 50 \\
\hline 2 & Cement $1+0,5 \% \mathrm{Li}_{2} \mathrm{CO}_{3}$ & 100 & 0.5 & 50 \\
\hline 3 & Cement $1+1,0 \% \mathrm{Li}_{2} \mathrm{CO}_{3}$ & 100 & 1.0 & 50 \\
\hline 4 & Cement $1+2,5 \% \mathrm{Li}_{2} \mathrm{CO}_{3}$ & 100 & 2.5 & 50 \\
\hline \multicolumn{5}{|c|}{$\mathrm{Cement} 2$} \\
\hline 5 & Cement $2+0,5 \% \mathrm{Li}_{2} \mathrm{CO}_{3}$ & 100 & 0.5 & 50 \\
\hline 6 & Cement $2+1,0 \% \mathrm{Li}_{2} \mathrm{CO}_{3}$ & 100 & 1.0 & 50 \\
\hline 7 & Cement $2+2,5 \% \mathrm{Li}_{2} \mathrm{CO}_{3}$ & 100 & 2.5 & 50 \\
\hline 8 & C & 100 & 0.0 & 50 \\
\hline
\end{tabular}

The heat evolution of samples was estimated by using the eight-channel isothermic-shell calorimeter TAM AIR. The researches were conducted on the samples of the cement paste with a mass of approximately 4 grams. Hardening of the samples was carried out at the constant increased temperature of $40^{\circ} \mathrm{C}$. The readings of the power of the heat flow in the course of the research were fixed with an interval of 30 seconds.

\section{Results}

According to the results of measurements of the heat flow at the early stage of hydration of the studied cement systems the corresponding exothermic curves (figure 1) and also the integral charts of the total heat energy released as a result of the reaction (figure 2) have been created. 


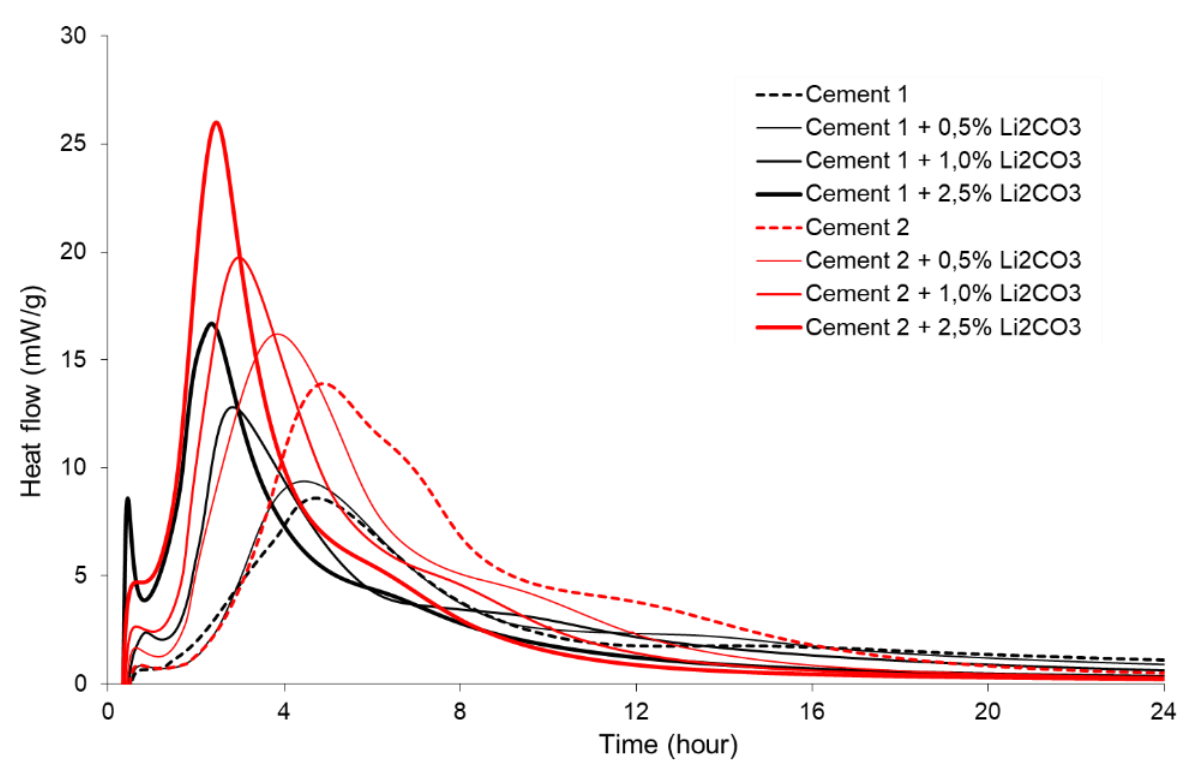

Fig. 1. The charts of the heat flow in the course of hydration of the studied compositions.

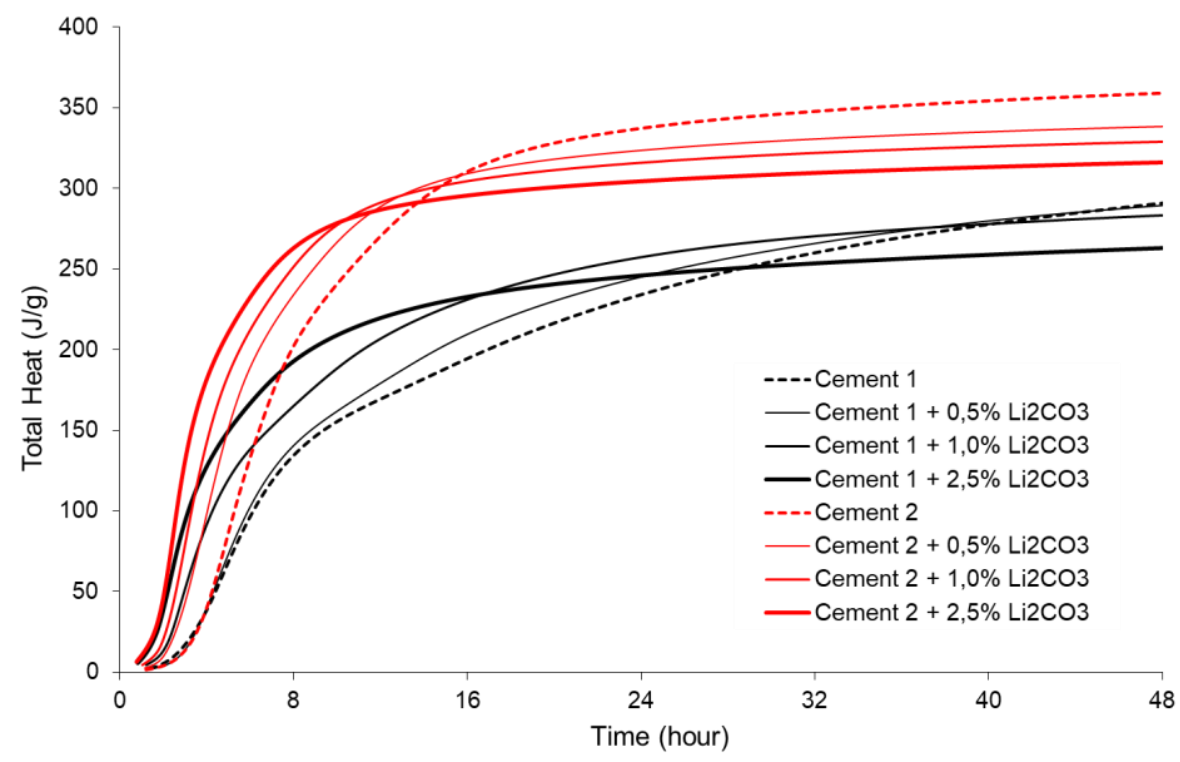

Fig. 2. The integral charts of the heat evolution of the studied compositions.

\section{Discussion}

The received charts indicate more intensive course of reaction of hydration for the samples on the basis of Cement 2 that, at the similar phase and mineral composition of the two samples of cement, is explained by a finer grinding of particles in the sample on the basis of Cement 2. The increase in the specific surface area results in an increase in the reactive capacity of the binder [2]. 
The received charts of the heat evolution of samples with an admixture indicate almost the linear increase in reaction velocity at the early stages of hydration at the increased dosage of the admixture of lithium carbonate from $0.5 \%$ to $2.5 \%$. The similar effect is observed in the first $2 \ldots 8$ hours for all the studied cement samples. Because of the fact that at the plants of the reinforced concrete goods production the products are exposed to thermal treatment in this particular time interval, $\mathrm{Li}_{2} \mathrm{CO}_{3}$ has the potential of being used as the accelerating admixture in concretes for the purpose of decreasing the duration of thermal treatment, or decreasing the temperature of the storage of samples during the thermal treatment in plant conditions.

At this stage of the present research the approximate accelerating effect of the admixture effect can be previously estimated by calculation of time saving required for the allocation of the thermal energy $\mathrm{Q}$ at the hydration according to the following formula [5]:

$$
E(Q)=\frac{T_{k}(Q)-T_{y}(Q)}{T_{k}(Q)} * 100 \%
$$

where $E(Q)$ - the accelerating effect, $T_{k}(Q)$ - the timepoint when the set heat evolution $Q$ for the control composition is reached, $T_{y}(Q)$ - the timepoint when the set heat evolution $Q$ for the composition with an accelerating admixture is reached. Thus, for example, for the achievement of the thermal energy of $200 \mathrm{~J} / \mathrm{g}$, for the composition 4 on the basis of Cement 1 with an admixture in the maximum dosage the $9 \mathrm{~h}$. will be needed, while for the composition $1-17$ h. $47.05 \%$. The similar results for the samples on the basis of Cement 2 will be 5 and 8 hours respectively. Thus, the accelerating effect for the achievement by the similar samples of the preset value of thermal energy will be $47.05 \%$ and $37.5 \%$ respectively for the samples on the basis of Cement 1 and Cement 2.

\section{Conclusions}

In the course of the research study it was discovered that at the increased temperature $\left(40{ }^{\circ} \mathrm{C}\right)$ of the storage of samples on the basis of cement binder the almost linear increase in intensity of heat evolution at the early stages of hydration by an increase in the dosage of the admixture of lithium carbonate $\left(\mathrm{Li}_{2} \mathrm{CO}_{3}\right)$ entered into the composition of the mixture within the studied range of dosages from $0.5 \%$ to $2.5 \%$ is observed. Taking into account the experimental data [8] obtained earlier by the group of authors about the increase in the efficiency of the effect of this admixture on the speed of the exothermic reaction at the increased temperature regime of the storage of samples, it is possible to draw a conclusion that the admixture of the lithium carbonate has the potential of being used for the solving of the problem of decreasing the energy capacity of the process of the thermal treatment of the concrete products and constructions during their manufacture in plant conditions.

In the event that the subsequent researches of the physical and mechanical characteristics and the characteristics of durability of the control samples studied within the present research show the positive results, it will allow to provide the energy saving at the hydrothermal processing of the concrete constructions by reducing the time or decreasing the temperature of processing.

\section{Acknowledgement}

The work was supported by the Ministry of Education and Science of Russia (\#14.Z56.3456MK), all tests were carried out on the equipment of The Head Regional Shared Research Facilities of the Moscow State University of Civil Engineering. 


\section{References}

1. V.G. Mikylskiy, G.I. Gorchyakov, V.V. Kozlov, Building materials (ASV, Moscow, 2002)

2. A.V. Volgenskiy, Mineral binder materials (Stroyizdat, Moscow, 1986)

3. V.G. Batrakov, Modified concrete (Astra-seven, Moscow, 1998)

4. U.M. Bazhenov, Concrete technology (ASV, Moscow, 2007)

5. A.O. Adamtsevich, S.A. Pashkevich, A.P. Pustovgar, Civ. Eng. M. 38, 36-42 (2013)

6. H. Taylor, Cement chemistry (Mir, Moscow, 1996)

7. O.A. Kudelko, St.U. Polockiy, Vestnik 12, 28-37 (2010)

8. A.O. Adamtsevich, L. Shilova, IOP Conf. Ser.: Earth Environ 90, 012152 (2017)

9. I. Pane, W. Hansen, Cem. Concr. Res. 35-6, 1155-1164 (2005)

10. Q. Xu, Thermochim. Acta 499-1-2, 91-99 (2010)

11. J. Cheung, Cem. Concr. Res. 41-12, 1289-1309 (2011)

12. P. Morabito, Rilem report, 1-25 (1998)

13. S. Medvescek, V. Kaucic, A. Meden, Acta Chim.Slov. 64-2, 381-396 (2017) 